\title{
Development of a split fluorescent protein-based RNA live-cell imaging system to visualize mRNA distribution in plants
}

\author{
Nien-Chen Huang, Kai-Ren Luo and Tien-Shin Yu* (1)
}

\begin{abstract}
Background: RNA live-cell imaging systems have been used to visualize subcellular mRNA distribution in living cells. The RNA-binding protein (RBP)-based RNA imaging system exploits specific RBP and the corresponding RNA recognition sequences to indirectly label mRNAs. Co-expression of fluorescent protein-fused RBP and target mRNA conjugated with corresponding RNA recognition sequences allows for visualizing mRNAs by confocal microscopy. To minimize the background fluorescence in the cytosol, the nuclear localization sequence has been used to sequester the RBP not bound to mRNA in the nucleus. However, strong fluorescence in the nucleus may limit the visualization of nucleus-localized RNA and sometimes may interfere in detecting fluorescence signals in the cytosol, especially in cells with low signal-to-noise ratio.
\end{abstract}

Results: We eliminated the background fluorescence in the nucleus by using the split fluorescent protein-based approach. We fused two different RBPs with the N- or C-terminus of split fluorescent proteins (FPs). Co-expression of RBPs with the target mRNA conjugated with the corresponding RNA recognition sequences can bring split FPs together to reconstitute functional FPs for visualizing target mRNAs. We optimized the system with minimal background fluorescence and used the imaging system to visualize mRNAs in living plant cells.

Conclusions: We established a background-free RNA live-cell imaging system that provides a platform to visualize subcellular mRNA distribution in living plant cells.

Keywords: RNA live-cell imaging, RNA-binding protein, Split fluorescent proteins, Mobile mRNAs, Plasmodesmata, Agro-infiltration

\section{Background}

Most cells transport mRNAs to specific subcellular compartments for localized RNA translation. Instead of transporting a quantity of proteins, the transport of mRNA provides an efficient strategy to distribute proteins to specific subcellular compartments. In eukaryotic cells, asymmetric mRNA localization is a conserved mechanism to create translation hotspots for regulating spatial gene expression in response to environmental

*Correspondence: tienshin@gate.sinica.edu.tw

Institute of Plant and Microbial Biology, Academia Sinica, Taipei 11529, Taiwan cues [1]. The intracellular mRNA asymmetric distribution in plants can be extended to the intercellular level in which specific plant mobile mRNAs are transcribed in local tissues and undergo long-distance movement via phloem to exert non-cell autonomous functions, including regulation of leaf development [2], floral transition [3, 4], and potato tuber formation [5]. Thus, understanding the mRNA subcellular distribution may provide information to unravel RNA logistics and post-transcriptional gene regulation.

In living plant cells, direct visualizing of mRNAs by microscopy is challenging. Many approaches have been developed that allow visualizing mRNAs in living cells. original author(s) and the source, provide a link to the Creative Commons licence, and indicate if changes were made. The images or other third party material in this article are included in the article's Creative Commons licence, unless indicated otherwise in a credit line to the material. If material is not included in the article's Creative Commons licence and your intended use is not permitted by statutory regulation or exceeds the permitted use, you will need to obtain permission directly from the copyright holder. To view a copy of this licence, visit http://creativecommons.org/licenses/by/4.0/. The Creative Commons Public Domain Dedication waiver (http://creativeco mmons.org/publicdomain/zero/1.0/) applies to the data made available in this article, unless otherwise stated in a credit line to the data. 
Direct labeling of mRNAs can be achieved by incorporating in vitro-synthesized mRNA with fluorescein-labeled nucleotides or introducing molecular beacons into cells to hybridize with the target mRNA [6,7]. However, these in vitro RNA labeling systems require invasive injection of labeled RNA into plant cells such as microinjection or particle bombardment. In addition, the in vitro-synthesized RNAs may behave differently from the in vivo-transcribed RNAs because the RNA synthesized in vitro may bypass the RNA modification occurring in the nucleus, which may change the properties of RNA.

Alternatively, RNA can be indirectly visualized by an RNA aptamer-based approach. In this system, the target mRNA is genetically modified by tagging with an RNA aptamer recognized by RNA-binding proteins (RBPs). Co-expression of fluorescent proteins (FPs) conjugated with RBPs with aptamer-tagged mRNA allows for indirect labelling of mRNA in living cells. MCP, a coat protein derived from MS2 bacteriophage with RNA-binding activity, and the stem loop structures recognized by MCP have been widely used to monitor mRNA localization in yeast, fruit fly, mammals and plants [8-13]. To reduce the background GFP fluorescence detected in the cytosol, the nuclear localization sequence (NLS) has been used to sequester the MCP-GFP not bound to RNA in the nucleus $[8,13]$. In addition, the signal-to-noise ratio of RNA detected in the cytosol can be greatly improved by the plant-specific NLS tightly restricting MCP in the nucleus [13].

Although the MCP-based approach has been successfully used to visualize the intracellular distribution of mobile and non-mobile mRNA in plants [13], the background GFP fluorescence derived from nucleus-localized MCP-GFP may interfere with detecting mRNA located close to the nucleus (Fig. 1A). In addition, cells that undergo active cell division are smaller and the nucleus is relatively large [14], so the high nucleus-to-cytoplasmic ratio may disturb the detection of RNA localization due to strong background GFP fluorescence in the nucleus (Fig. 1B).

In this study, we improved the RNA live-cell imaging system by eliminating the background GFP fluorescent in the nucleus. The application of this split FPs-based system detected differential subcellular distribution between mobile and non-mobile mRNAs. In addition, the split FPs-based system greatly improved the signal-to-noise ratio in the nucleus, which confers detection of mRNAs in the nucleus or at juxtanuclear region. Thus, our system broadens the application of RNA live-cell imaging system in plants.
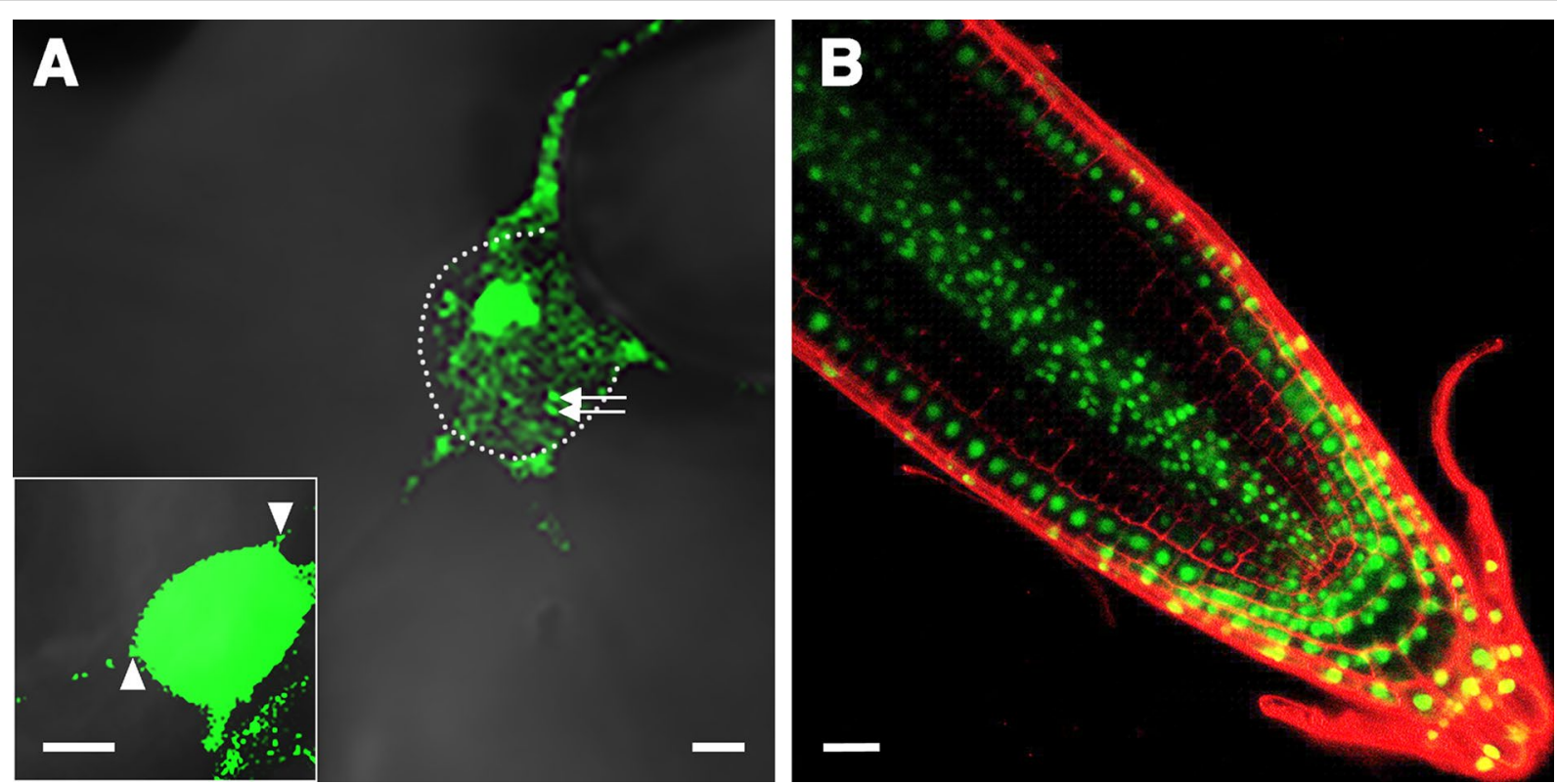

Fig. 1 Background GFP fluorescence disturbs observation of labeled mRNA. A Confocal microscopy of N. benthamiana leaves co-infiltrated with nucleus-localized MCP FD $^{-G F P}$ and FT-SL24, which is the coding sequences of Arabidopsis FLOWERING LOCUS T (FT) conjugated with 24 repeats of stem loop (SL) structures recognized by MCP [13]. The background fluorescence derived from nucleus-localized MCP-GFP interferes with the detection of potential FT mRNA foci (arrows) in the nucleus. Nucleus boundary is outlined with white dots. Bar $=2 \mu \mathrm{m}$. Inset, in cells with high accumulation level of MCP-GFP in the nucleus, high nucleus-to-cytoplasmic ratio of GFP fluorescence disturbs detection of FT mRNA foci (arrowheads) proximal to nucleus. Bar $=5 \mu \mathrm{m}$. B Roots of Arabidopsis transformant harboring constitutively expressed MCP FD-GFP. Note that in cells with high nucleus-to-cytoplasmic ratio, the background GFP fluorescence may interfere in mRNA localization in the cytosol. Scale bar $=20 \mathrm{~mm}$ 


\section{Results and discussion}

Development of split FP-based RNA live-cell imaging system

To develop the mRNA live-cell imaging system without background GFP fluorescence in the nucleus, we exploited the bimolecular fluorescence complementation system to reduce background GFP fluorescence derived from MCP-GFP not bound to mRNA. In this system, two different RBPs were fused with the N- or $\mathrm{C}$-terminus of split FPs to reduce the fluorescence produced from RBP-FPs not bound to mRNA. The target mRNA was flanked with the corresponding RNA recognition sequences of the RBPs. The interaction between RBPs and RNA recognition sequences may bring two split FPs together to reconstitute a mature FP (Fig. 2A).
We selected two coat proteins (CPs) of MS2 and PP7 bacteriophages, MCP and PCP, which specifically bind to an RNA hairpin structure of MBS and PBS, respectively [15]. MCP and PCP were conjugated with the $\mathrm{N}$-terminus fragment $\left(\mathrm{FP}_{\mathrm{N}}\right.$, amino acids $1-173$ from Venus) or $\mathrm{C}$-terminus fragment $\left(\mathrm{FP}_{\mathrm{C}}\right.$, amino acids 156-239 from SCFP3A) of the split FP protein [16]. To identify the optimized fusion proteins for the system, we generated different MCP/PCP-FP fusion proteins by flanking $\mathrm{FP}_{\mathrm{N}}$ or $\mathrm{FP}_{\mathrm{C}}$ with $\mathrm{MCP}$ or PCP (Fig. 2B). In addition, the NLS derived from Arabidopsis FD [13], which encodes a bZIP transcription factor [17], was used to locate MCP or PCP to the nucleus (Fig. 2B). To generate the target mRNAs that can be recognized by $\mathrm{MCP}$ and $\mathrm{PCP}$, the DNA fragments containing 12

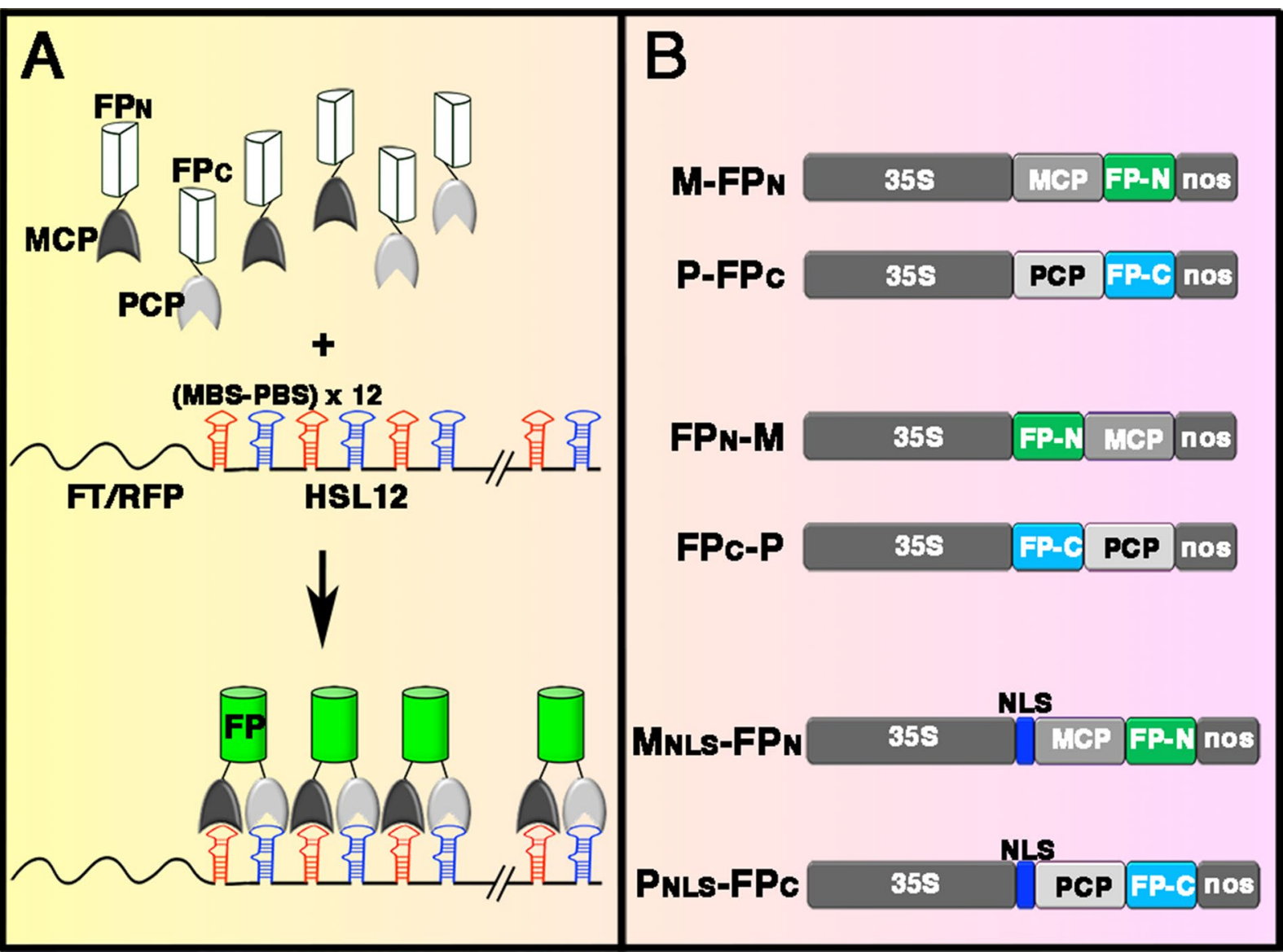

Fig. 2 Illustration of split fluorescent protein (FP)-based RNA live-cell imaging system. A MCP or PCP, the coat proteins of MS2 or PP7 bacteriophage, was fused with the $\mathrm{N}$ - or $\mathrm{C}$-terminus of split FPS, $\mathrm{FP}_{\mathrm{N}}$ or FP, respectively. The FT or RFP mRNA was conjugated with 12 copies of MBS-PBS, the hairpin structure recognized by MCP and PCP, to generate $F T_{H S L 12}$ or RFP ${ }_{H S L 12}$ chimeric RNA. The binding of MCP and PCP with the hairpin structure of MBS-PBS brings two split FPs together to reconstitute the functional FP for indirect visualization of mRNAs in living cells. B Illustration of the constructs of MCP (M) and PCP (P) fused with the N- or C-terminus of FP ${ }_{N}$ or FP. The nuclear localization sequence (NLS) from Arabidopsis FD was inserted to sequester MCP- or PCP-FP fusion proteins in the nucleus. The constructs were driven by a CaMV35S promoter and had an NOS terminator 


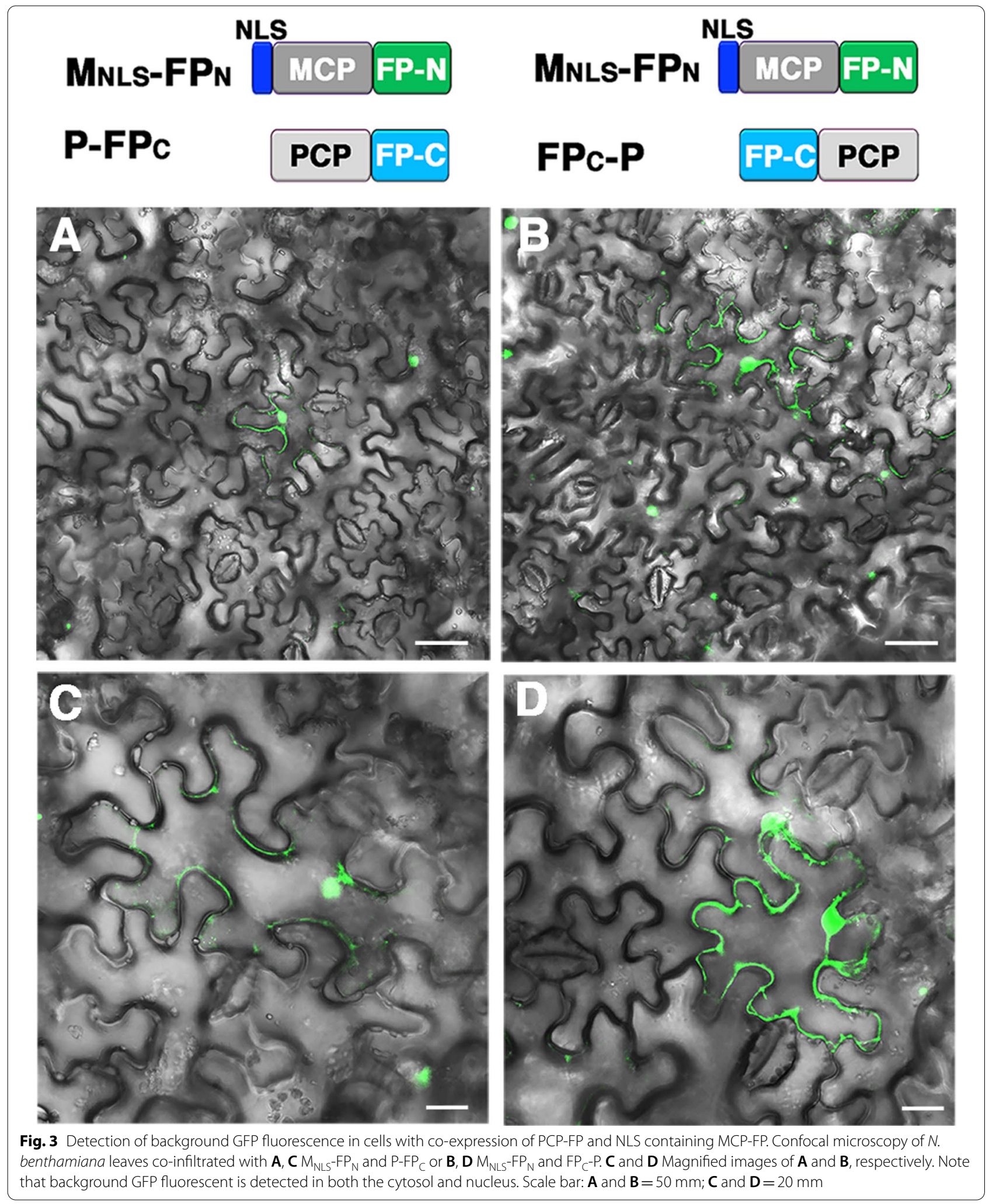




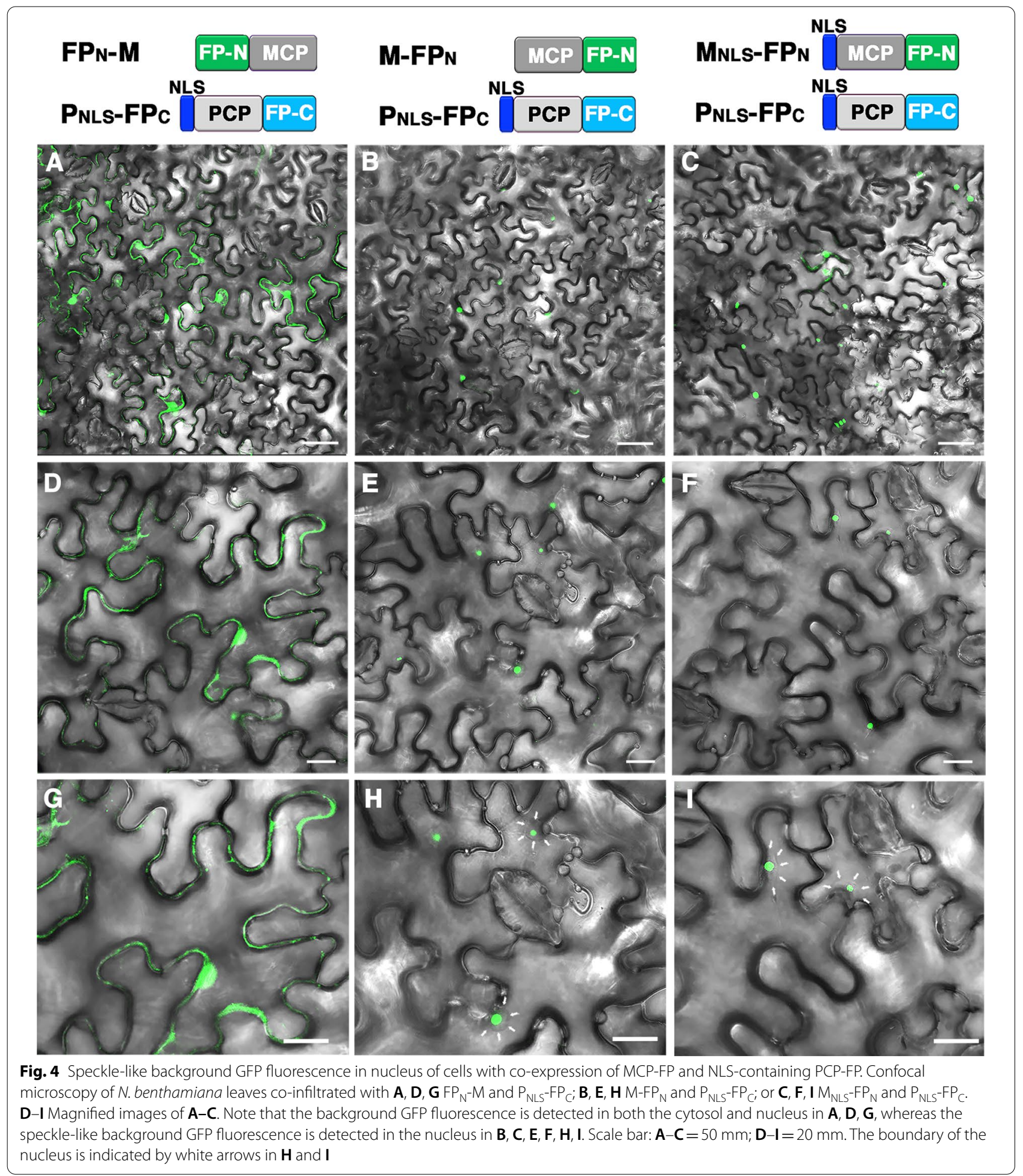

copies of MBS-PBS tandem repeats were conjugated with $F T$ or RFP cDNA to create $F T_{H S L 12}$ (FT-hybrid stem loops, $\underline{12}$ copies) or $R F P_{H S L 12}$, respectively (Fig. 2A).
Background GFP fluorescence was under the detection limit in cells expressing MCP-FP ${ }_{N}$ and PCP-FP

To identify the combinations of MCP and PCP with minimal background GFP fluorescence in plant cells, 


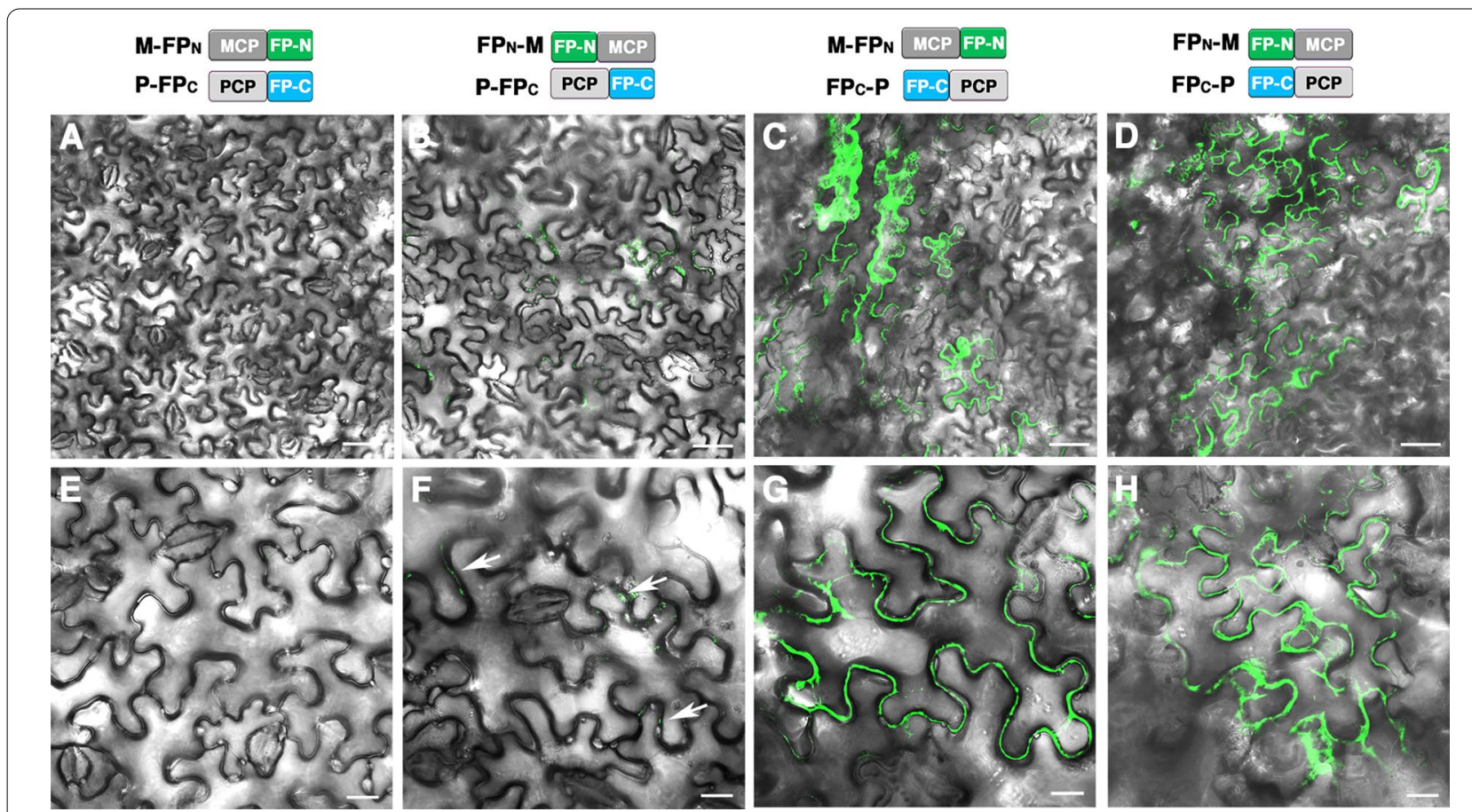

Fig. 5 GFP background fluorescence was not detected in cells with co-expression of $M-F P_{N}$ and P-FP $P_{C}$. Confocal microscopy of $N$. benthamiana

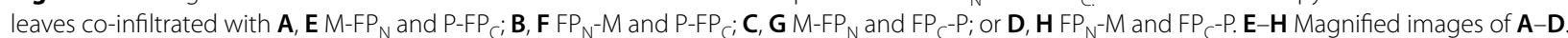
Note that background GFP is under the detection limit in $\mathbf{A}$, $\mathbf{E}$. The weak background GFP fluorescence is indicated by white arrows in $\mathbf{F}$. Scale bar: $\mathbf{A}-\mathbf{D}=50 \mathrm{~mm} ; \mathbf{E}-\mathrm{H}=20 \mathrm{~mm}$

Table 1 Summary of background GFP fluorescence detection with different combinations of split fluorescent proteins

\begin{tabular}{llll}
\hline MCP varieties & PCP varieties & Background & Fluorescence \\
\hline$M_{N L S}-F P_{N}$ & $P-F P_{C}$ & Yes & Nucleus, cytosol \\
$M_{N L S}-F P_{N}$ & $F P_{C}-P$ & $Y e s$ & Nucleus, cytosol \\
$F P_{N}-M$ & $P_{N L S}-F P_{C}$ & $Y e s$ & Nucleus, cytosol \\
$M-F P_{N}$ & $P_{N L S}-F P_{C}$ & $Y e s$ & Speckle in nucleus \\
$M_{N L S}-F P_{N}$ & $P_{N L S}-F P_{C}$ & $Y e s$ & Speckle in nucleus \\
$M-F P_{N}$ & $P-F P_{C}$ & No & Non-detectable \\
$F P_{N}-M$ & $P-F P_{C}$ & $Y e s$ & Cytosol \\
$M-F P_{N}$ & $F P_{C}-P$ & $Y e s$ & Nucleus, cytosol \\
$F P_{N}-M$ & $F P_{C}-P$ & $Y e s$ & Cytosol \\
\hline
\end{tabular}

we transiently expressed different MCP- and PCP-split FPs in leaves of 3-weak-old Nicotiana benthamiana by agro-infiltration and examined GFP fluorescence under a confocal laser scanning microscope at 3 days after infiltration. When NLS-containing $\mathrm{M}_{\mathrm{NLS}}-\mathrm{FP}_{\mathrm{N}}$ was coexpressed with $\mathrm{P}-\mathrm{FP}_{\mathrm{C}}$ or $\mathrm{FP}_{\mathrm{C}}-\mathrm{P}$, weak GFP fluorescence was detected in both the cytosol and nucleus (Fig. 3A$\mathrm{D})$, which suggests that the separation of MCP and $\mathrm{PCP}$ into different subcellular compartments may not significantly reduce the background GFP fluorescence. Consistently, when NLS-containing $\mathrm{P}_{\mathrm{NLS}}-\mathrm{FP}_{\mathrm{C}}$ was co-expressed with $\mathrm{FP}_{\mathrm{N}}-\mathrm{M}$, the background GFP fluorescence was again detected in the cytosol and nucleus (Fig. 4A, D, G). However, when $\mathrm{P}_{\mathrm{NLS}}-\mathrm{FP}_{\mathrm{C}}$ was co-expressed with $\mathrm{M}-\mathrm{FP}_{\mathrm{N}}$ or NLS-containing $\mathrm{M}_{\mathrm{NLS}}-\mathrm{FP}_{\mathrm{N}}$, the background GFP fluorescence that formed a speckle-like spot was detected only in the nucleus (Fig. 4B, C, E, F, H, I), which suggests that the topology of fusion proteins rather than subcellular localization may contribute to the background GFP fluorescence.

We next examined background GFP fluorescence in cells expressing MCP-FP and PCP-FP without NLS. When $\mathrm{M}-\mathrm{FP}_{\mathrm{N}}$ was co-expressed with $\mathrm{P}-\mathrm{FP}_{\mathrm{C}}$, we consistently obtained the images without detectable background GFP fluorescence (Fig. 5A and E). However, the other 3 combinations of MCP-FP and PCP-FP conferred weak (Fig. 5B and F) or strong GFP fluorescence (Fig. 5C, D, and G, H). We summarize these results in Table 1. Taken together, our results reveal that the combination of MCP-FP ${ }_{\mathrm{N}}$ and $\mathrm{PCP}-\mathrm{FP}_{\mathrm{C}}$ produced undetectable background GFP fluorescence. In addition, the combination of $\mathrm{P}_{\mathrm{NLS}}-\mathrm{FP}_{\mathrm{C}}$ with $\mathrm{M}-\mathrm{FP}_{\mathrm{N}}$ or $\mathrm{M}_{\mathrm{NLS}}-\mathrm{FP}_{\mathrm{N}}$ produced specklelike background GFP fluorescence in the nucleus, which 


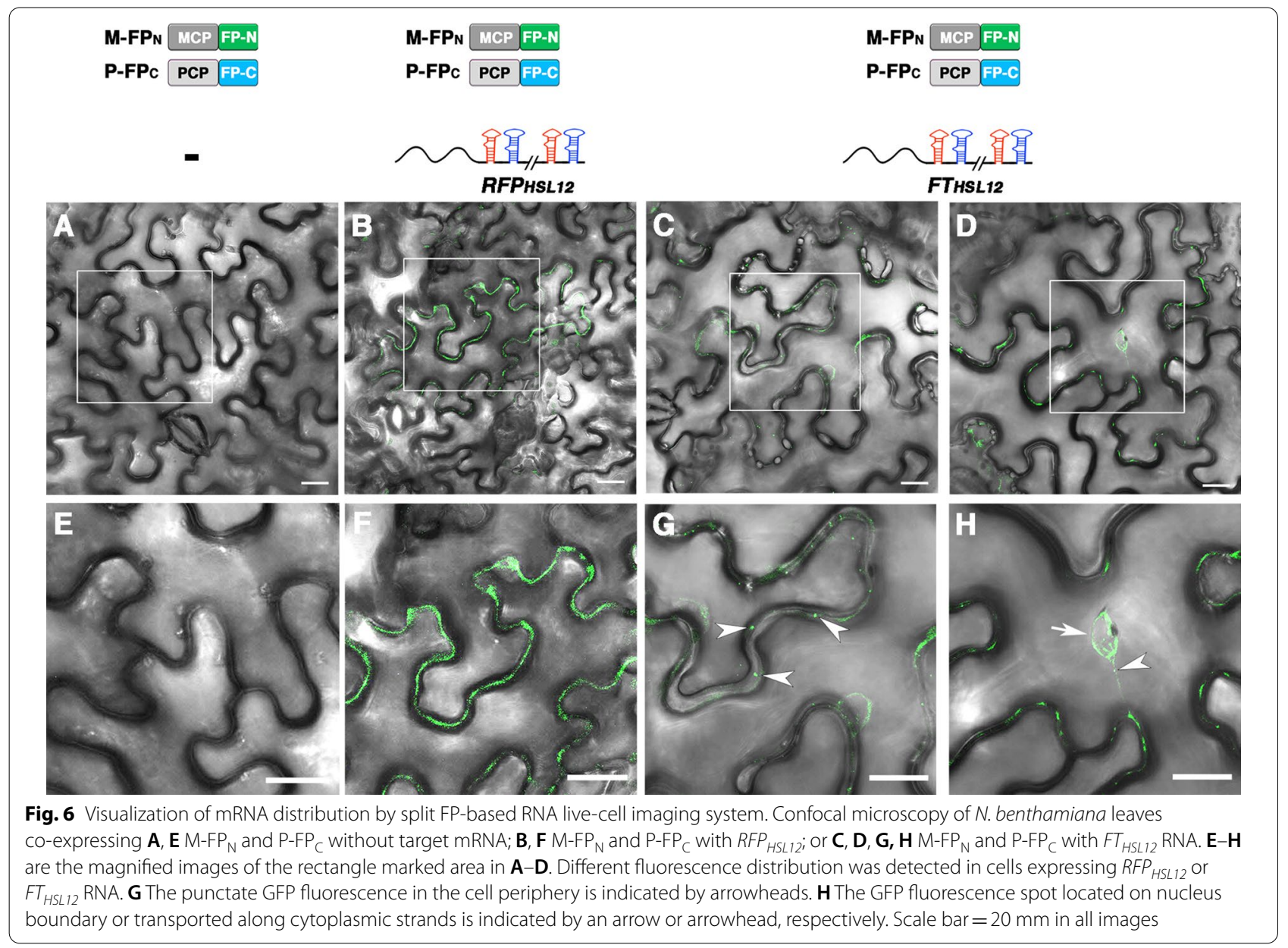

may also provide a useful positive control for the presence of the infiltrated constructs.

\section{Detection of mRNA localization in background-free split FP-based imaging system}

To verify the application of the split-FP system for localization of mRNAs, we co-infiltrated $\mathrm{M}-\mathrm{FP}_{\mathrm{N}}$ and $\mathrm{P}-\mathrm{FP}_{\mathrm{C}}$ with $F T_{H S L 12}$ or RFP ${ }_{H S L 12}$, two mRNAs with differential subcellular distribution pattern [13] in tobacco leaves. At 3 days after infiltration, no fluorescence was detected in control cells co-expressing $\mathrm{M}-\mathrm{FP}_{\mathrm{N}}$ and $\mathrm{P}-\mathrm{FP}_{\mathrm{C}}$ without mRNA (Fig. 6A, E). However, GFP fluorescence was detected in the cytosol of cells co-expressing $\mathrm{M}-\mathrm{FP}_{\mathrm{N}}$ and $\mathrm{P}^{-\mathrm{FP}_{\mathrm{C}}}$ with $R F \mathrm{P}_{\mathrm{HSL} 12}$ or $F T_{H S L 12}$ mRNA. Of note, the fluorescence in the cytosol showed distinct distribution patterns in cells expressing RFP ${ }_{H S L 12}$ or $F T_{H S L 12}$ mRNA: in cells expressing $R F P_{H S L 12}$, the fluorescence was evenly distributed at the cell periphery (Fig. 6B, F), whereas with $F T_{H S L 12}$, the fluorescence showed a punctate distribution
(Fig. 6C, G). These subcellular distribution patterns were reminiscent of previous MS2-based mRNA live-cell imaging [13]. However, in the split FP-based imaging system, the GFP fluorescence spots were detected inside or in the boundary of the nucleus (Fig. 6D-H), which were not detected in the previous MS2-based system [13]. These results suggest the broader use of a split FP-based imaging system for visualizing mRNA distribution.

We further verified the application of the split FPbased imaging system with speckle-like background GFP fluorescence for mRNA visualization. In control cells co-expressing $\mathrm{M}_{\mathrm{NLS}}-\mathrm{FP}_{\mathrm{N}}$ and $\mathrm{P}_{\mathrm{NLS}}-\mathrm{FP}_{\mathrm{C}}$, speckle-like GFP fluorescence was detected in the nucleus (Fig. 7A and $C$ ), whereas in cells co-expressing $\mathrm{M}_{\mathrm{NLS}}-\mathrm{FP}_{\mathrm{N}}$ and $\mathrm{P}_{\mathrm{NLS}}-\mathrm{FP}_{\mathrm{C}}$ with $F T_{H S L 12} \mathrm{mRNA}$, the GFP fluorescence was detected in the cytosol with a punctate distribution pattern (Fig. 7B and D). Of note, GFP fluorescence spots were detected in the nucleus (Fig. 7D), suggesting that 


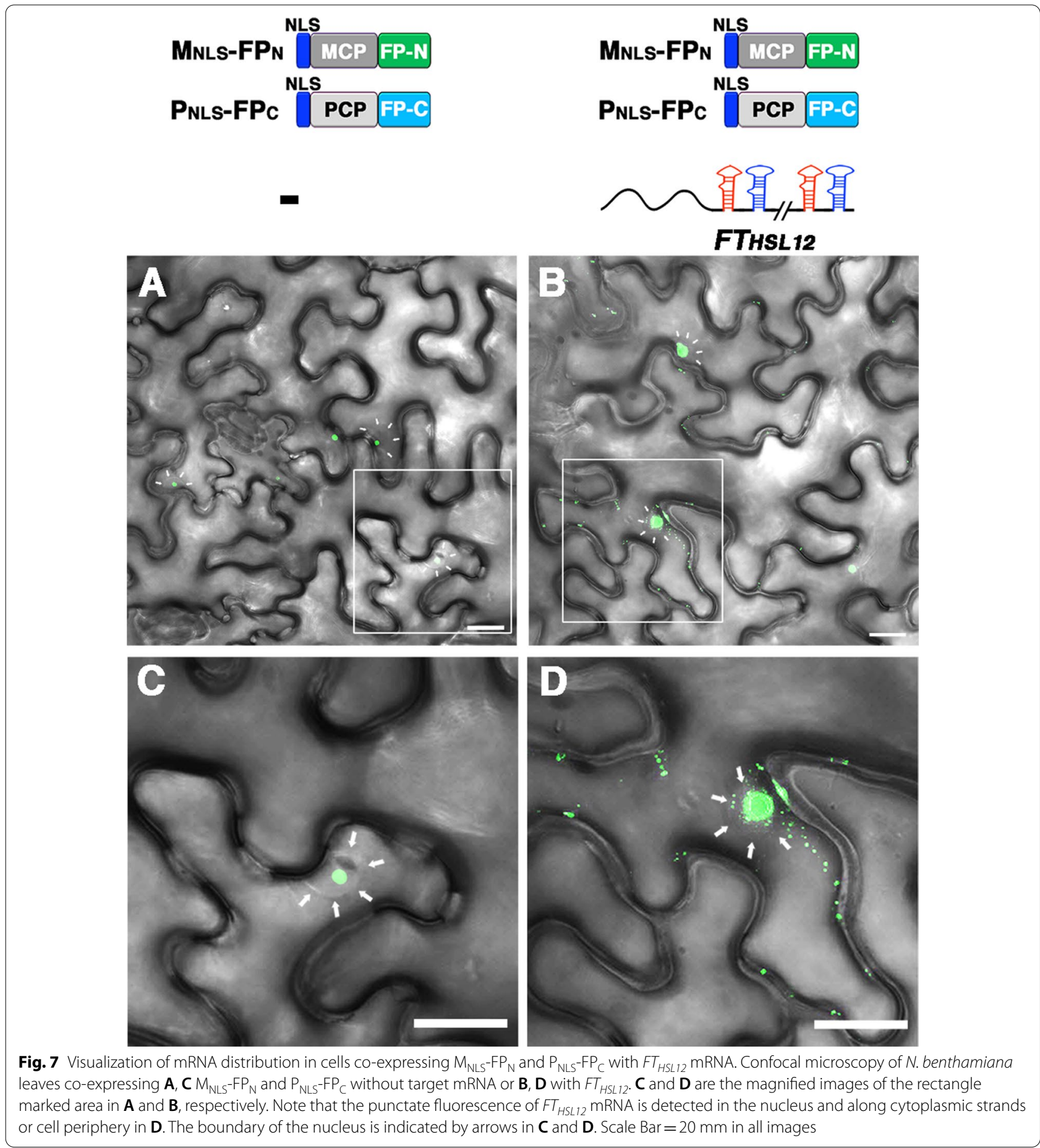

the speckle-like background GFP may not greatly disturb mRNA visualization in the nucleus.

\section{Conclusions}

We have established a split FP-based RNA live-cell imaging system for visualizing subcellular mRNA distribution in living plant cells. This system eliminates the background GFP fluorescence in the nucleus. We applied this system to monitor intracellular transport of mobile 
and non-mobile mRNA. In addition, this system enables the detection of mRNAs near the nucleus. Our method broadens the application of RBP-based RNA imaging system in living plant cells.

\section{Methods}

\section{Plant materials and growth conditions}

Nicotiana benthamiana plants were grown in a growth chamber under $27^{\circ} \mathrm{C}, 16-\mathrm{h} / 8$-h day/night cycles and light intensity $100 \mu \mathrm{mol} \mathrm{m}{ }^{-2} \mathrm{~s}^{-1}$. The 3-week-old plants were used for agro-infiltration assay.

\section{Plasmid construction and Arabidopsis transformation}

The DNA fragments of MCP and PCP were PCR-amplified with the following primers: MCP-For (5'-GGATCC ATGGCTTCTAACTTTACTCAGTTCG-3'), MCP-Rev (5'-CTCGAGGTAGATGCCGGAGTTTGCTGCGAT T-3'), PCP-For (5'-GGATCCATGTCCAAAACCATC GTTCTTTCGG-3'), PCP-Rev (5'-CTCGAGACGGCC CAGCGGCACAAGGTTGACG-3'). The DNA fragments of MCP and PCP were confirmed by sequencing and cloned into split FP-containing binary vectors pVYNE, pVYNE(R), pSCYCE, or $\operatorname{PSCYCE}(\mathrm{R})$ [16] to generate $\mathrm{M}-\mathrm{FP}_{\mathrm{N}}, \mathrm{FP}_{\mathrm{N}}-\mathrm{M}, \mathrm{P}-\mathrm{FP}_{\mathrm{C}}$ and $\mathrm{FP}_{\mathrm{C}}-\mathrm{P}$, respectively. The C-terminal fragment (211-240 a.a.) of Arabidopsis $\mathrm{FD}$, which contains the nuclear localization sequence (NLS) [13], was inserted in $\mathrm{M}-\mathrm{FP}_{\mathrm{N}}$ or $\mathrm{P}-\mathrm{FP}_{\mathrm{C}}$ to generate $\mathrm{M}_{\mathrm{NLS}}-\mathrm{FP}_{\mathrm{N}}$ and $\mathrm{P}_{\mathrm{NLS}}-\mathrm{FP}_{\mathrm{C}}$, respectively.

For the 12 copies of the MBS-PBS hybrid stem loop sequence (HSL12), the Pcr4-12X-MBS-PBS [15] DNA was digested with BamHI and SpeI, followed by the Klenow fill-in reaction. The 1402-bp HSL12 fragment was gel-eluted and ligated with the binary vector pCAMBIA1390 containing the 35S-FT or 35S-RFP to form the p1390-35S-FT $T_{H S L 12}$ or p1390-35S-RFP $P_{H S L 12}$ construct, respectively.

\section{Agro-infiltration of $N$. benthamiana}

Agrobacterium tumefaciens strain AGL1 carrying individual constructs was cultured in $20 \mathrm{~mL}$ LB broth $(10 \mathrm{~g} / \mathrm{L}$ tryptone, $5 \mathrm{~g} / \mathrm{L}$ yeast extract, $10 \mathrm{~g} / \mathrm{L} \mathrm{NaCl}$ ) containing $50 \mu \mathrm{g} \mathrm{mL}{ }^{-1}$ kanamycin, $10 \mathrm{mM}$ MES, pH 5.7 and $20 \mu \mathrm{M}$ acetosyringone at $28^{\circ} \mathrm{C}$ with $220 \mathrm{rpm}$ shaking for 2 days. Bacteria were pelleted by centrifugation and resuspended in infiltration medium (10 mM MgCl2, $10 \mathrm{mM} \mathrm{MES,} \mathrm{pH}$ 5.7, and $200 \mu \mathrm{M}$ acetosyringone) to $\mathrm{OD} 600=1.0$. The bacterial solution was placed at room temperature for at least $1 \mathrm{~h}$. For agro-infiltration, the bacteria solution was infiltrated into the abaxial side of the $4^{\text {th }}$ or $5^{\text {th }}$ leaves of 3 -week-old $N$. benthamiana by using a needle-removed 5 -mL syringe. For co-infiltration with 2 or 3 different constructs, different bacterial solution or infiltration media were mixed at a 1:1 volume ratio and infiltrated into leaves. The infiltrated plants were cultured in growth chambers for 3 days, then infiltrated leaves were excised for confocal laser scanning microscopy.

\section{Confocal laser scanning microscopy}

GFP fluorescence was observed by confocal laser scanning microscopy (LSM880, Carl Zeiss) with the argon laser set to 488/500-530 for excitation/emission.

\begin{abstract}
Abbreviations
FP: Fluorescent protein; MCP: MS2 bacteriophage coat protein; PCP: PP7 bacteriophage coat protein; MBS: MCP binding sequences; PBS: PCP binding sequences; NLS: Nuclear localization sequence; HSL: MBS-PBS hybrid stem loop sequences.
\end{abstract}

\section{Acknowledgements}

We thank Mrs. Mei-Jane Fang for assistance in troubleshooting the confocal microscopy.

\section{Authors' contributions}

$\mathrm{NCH}$ and TSY planed the research. NCH carried out experiments and drafted the manuscript. KRL carried out experiments of RFP localization. TSY contributed to writing the manuscript. All authors read and approved the final manuscript

\section{Funding}

This work was supported by grants from the Ministry of Science and Technology, Taiwan (MOST 108-2311-B-001-025-MY3) and Academia Sinica, Taiwan (AS-TP-108-L01)

\section{Availability of data and materials}

All data and materials are available upon request to TSY (tienshin@gate.sinica. edu.tw').

\section{Declarations}

Ethics approval and consent to participate Not applicable.

\section{Consent for publication}

All authors read and agreed to publish the final manuscript.

Competing interests

The authors declare that they have no competing interests.

Received: 20 October 2021 Accepted: 24 January 2022

Published online: 08 February 2022

\section{References}

1. Das S, Vera M, Gandin V, Singer RH, Tutucci E. Intracellular mRNA transport and localized translation. Nat Rev Mol Cell Biol. 2021;22:483-504.

2. Haywood V, Yu TS, Huang NC, Lucas WJ. Phloem long-distance trafficking of GIBBERELLIC ACID-INSENSITIVE RNA regulates leaf development. Plant J. 2005:42:49-68

3. Lu KJ, Huang NC, Liu YS, Lu CA, Yu TS. Long-distance movement of Arabidopsis FLOWERING LOCUS T RNA participates in systemic floral regulation. RNA Biol. 2012;9:653-62.

4. Huang NC, Jane WN, Chen J, Yu TS. Arabidopsis thaliana CENTRORADIALIS homologue (ATC) acts systemically to inhibit floral initiation in Arabidopsis. Plant J. 2012;72:175-84.

5. Banerjee AK, Chatterjee M, Yu Y, Suh SG, Miller WA, Hannapel DJ. Dynamics of a mobile RNA of potato involved in a long-distance signaling pathway. Plant Cell. 2006;18:3443-57. 
6. Christensen N, Tilsner J, Bell K, Hammann P, Parton R, Lacomme C, Oparka K. The $5^{\prime}$ cap of tobacco mosaic virus (TMV) is required for viron attachment to the actin/endoplasmic reticulum network during early infection. Traffic. 2009;10:536-51.

7. Göhring J, Jacak J, Barta A. Imaging of endogenous messenger RNA splice variants in living cells reveals nuclear retention of transcripts inaccessible to nonsense-mediated decay in Arabidopsis. Plant Cell. 2014;26:754-64.

8. Buxbaum AR, Haimovich $\mathrm{G}$, Singer RH. In the right place at the right time: visualizing and understanding mRNA localization. Nat Rev Mol Cell Biol. 2015;16:95-109.

9. Bertrand E, Chartrand P, Schaefer M, Shenoy SM, Singer RH, Long RM. Localization of ASH1 mRNA particles in living yeast. Mol Cell. 1998;2:437-45.

10. Forrest KM, Gavis ER. Live imaging of endogenous RNA reveals a diffusion and entrapment mechanism for nanos mRNA localization in Drodophila. Curr Biol. 2003;13:1159-68.

11. Park HY, Lim H, Yoon YJ, Follenzi A, Nwokafor C, Lopez-Jones M, Meng X, Singer RH. Visualization of dynamics of single endogenous mRNA labeled in live mouse. Science. 2014;343:422-4.

12. Hamada S, Ishiyama K, Choi S-B, Wang C, Singh S, Kawai N, Franceschi VR, Okita TW. The transport of prolamine RNAs to prolamine protein bodies in living rice endosperm cells. Plant Cell. 2003;15:2253-64.

13. Luo KR, Huang NC, Yu TS. Selective targeting of mobile mRNAs to plasmodesmata for cell-to-cell movement. Plant Physiol. 2018;177:604-14.

14. Trombetta W. The nuclear ratio in developing plant cells. Am J Bot. 1939;26:519-29

15. Wu B, Chen J, Singer RH. Background free imaging of single mRNAs in live cells using split fluorescent proteins. Sci Rep. 2014;4:3615.

16. Waadt R, Schmidt LK, Lohse M, Hashimoto K, Bock R, Kudla J. Multicolor bimolecular fluorescence complementation reveals simultaneous formation of alternative CBL/CIPK complexes in planta. The Plant J. 2008;56:505-16.

17. Abe M, Kobayashi Y, Yamamoto S, Daimon Y, Yamaguchi A, Ikeda Y, Ichinoki H, Notaguchi M, Goto K, Araki T. FD, a bZIP protein mediating signals from the floral pathway integrator FT at the shoot apex. Science. 2005;309:1052-6.

\section{Publisher's Note}

Springer Nature remains neutral with regard to jurisdictional claims in published maps and institutional affiliations.

Ready to submit your research? Choose BMC and benefit from:

- fast, convenient online submission

- thorough peer review by experienced researchers in your field

- rapid publication on acceptance

- support for research data, including large and complex data types

- gold Open Access which fosters wider collaboration and increased citations

- maximum visibility for your research: over $100 \mathrm{M}$ website views per year

At BMC, research is always in progress.

Learn more biomedcentral.com/submissions 